\title{
Habituated: A Merleau-Pontian Analysis of the Smartphone
}

\author{
Maria Howard and Hilary Bussell
}

\begin{abstract}
This paper offers a phenomenological account of our relationship to our smartphones rooted in the work of philosophers Maurice Merleau-Ponty (1908-1961) and Drew Leder (1954-). We argue that the nature of this relationship has implications for the ways we conceptualize and promote information literacy in the era of mobile ubiquity. After reviewing recent LIS literature on mobile devices in libraries, we discuss Merleau-Ponty's notion of the habit body and Drew Leder's development of the Merleau-Pontian concept of incorporation. We then apply these concepts to our use of smartphones, paying particular attention to the incorporation of the smartphone in our bodily habit and what this means for our relationship to the information we access on this device. The paper concludes by considering how the insights from this analysis of the smartphone could be integrated into existing information literacy conversations through the lens of dispositions.
\end{abstract}

\section{INTRODUCTION}

Over the last decade, there has been a great deal written in library and information science (LIS), education, and related fields on how the increasing prevalence of mobile devices has changed the way people, particularly teenagers and young adults, consume and interact with information. Hyperconnectedness to information via our mobile devices is often heralded as a positive development that libraries should embrace. In this paper, we challenge this general sentiment. Although increased information access offers considerable advantages, we need to operate from a fuller understanding of the way in which that information is accessed, as well as the 
unintended, often unseen, effects of this method of access. This requires an understanding of the role of embodiment in information access.

This paper will apply concepts from philosophical phenomenology developed by Maurice Merleau-Ponty (1908-1961) and Drew Leder (1954-), specifically the concepts of bodily habit and incorporation, to our relationship to smartphones. While some research in LIS has adopted the methodology of empirical phenomenology popular in the social sciences, little work has been offered that adopts philosophical phenomenological concepts. Empirical phenomenology in the social sciences is characterized by the researcher's attempt to suspend any preconceived notion of the phenomenon she tries to study, followed by a discussion of themes that arise during the course of her study. This normally takes the form of the researcher interviewing subjects on their experience or thoughts of some phenomenon and then looking for common patterns in reports of experience (see, for instance, Groenewald 2004; Hein and Austin 2001; Kafle 2013). In order to offer the analysis necessary to understand our relationship to our smartphones, however, we adopt an explicitly Merleau-Pontian phenomenological framework. Central to this framework is a commitment to the suspension of what phenomenologists call the "natural attitude" and an understanding of the intentionality of embodied consciousness when we analyze a particular phenomenon. In this study, we will analyze the ways in which our smartphones appear to us in our everyday experience. We will attempt "to articulate what was previously just lived out" (Taylor 2005, 32), and, using the work of Leder and Merleau-Ponty, we will render visible certain unseen facets of our bodies' relationships to our smartphones and explore how elements of this relationship might affect the way in which we conceptualize the use of our smartphones. ${ }^{1}$ We will argue that the nature of this relationship has implications for the ways we conceptualize and promote information literacy in the era of mobile ubiquity.

\section{Mobile Devices AND Libraries}

Although internet-enabled mobile devices have been around since the 1990 s, they gained widespread adoption in the first decade of the twentyfirst century (Fling 2009). In 2015, the Pew Research Center reported that smartphone ownership among adults had risen to 68 percent from 35 percent just four years earlier (Anderson 2015). Discussions about the impact of these devices on every aspect of our lives have become almost as ubiquitous as the devices themselves.

Much has been written in the LIS literature over the past decade about the ways that mobile devices are changing information seeking and retrieval, and the implications for academic libraries in providing outreach, reference, instruction, and access to resources (see Barnhart and Pierce 2011; Bridges, Gascho Rempel, and Griggs 2010; Dold 2016; Dukic, Chiu, 
and Lo 2015; Murray 2010). The rise of mobile devices has prompted many to consider how librarians and educators can utilize them to reach the current generation of students. A 2014 EDUCAUSE study of undergraduates at 214 institutions found that 86 percent own smartphones, and 59 percent use them for coursework (Dahlstrom, Walker, and Dziuban 2014, 15). A full five years before this, in "Libraries and the Mobile Revolution," Michelle Leigh Jacobs recounts walking around the library and noticing that almost every student has a mobile phone in front of them, along with their other study materials. She argues that today's library users "[expect] everything at their fingertips regardless of where they are," and that libraries should strive to meet this expectation by making their resources and content available through mobile devices (Jacobs 2009, 288). A number of subsequent studies support this claim. Hudson (2010) found that a majority of students said they would make use of reference services over their mobile devices if it were available. A study from the same year indicated that smartphone adoption was increasing sharply and students expect services and resources to be available to them "on the go" (S. Wilson and McCarthy 2010, 225). More recently, a survey of undergraduates at The College of New Jersey found that 99 percent of respondents own some sort of mobile device, and a majority want to be able to search databases on these devices (Cowell and Mi 2016).

Much of the literature falls somewhere on the spectrum from cautiously optimistic to very enthusiastic about how mobile devices will change how library users do research and find information, while acknowledging that it is impossible to predict exactly what this change will look like. In a passage that reverberates in our current political moment, Jacobs writes, "It is okay not to know how these new tools will reshape access to knowledge. If five years ago, someone told you that major newspapers would close their doors and cease publication and that some of the world's most prominent news services, even the president of the USA would communicate to the public through a series of 140 character comments, you would have deemed the idea highly improbable and ridiculous" (2009, 288-89). She continues, "This can be a very exciting time for libraries. Information is in demand $24 / 7$ because of the advances in technology. There is almost no way to escape 'being wired,' and we can cash in on this" (290).

Discussions around mobile devices are often framed in terms of opportunities or imperatives for libraries. Mobile devices offer libraries and universities the opportunity to transform learning and engagement, and to contribute to student success (Foley and Bertel 2015; Lippincott 2010). Libraries can use mobile devices to promote participatory culture and new forms of engagement with their communities (Hopkins et al. 2015), and to make their resources more accessible (Hennig 2016). Libraries must adapt themselves to Millennial expectations for real-time, on-demand services (Breeding 2006); they should move quickly in order to keep pace 
with mobile development and establish leadership in this area on their campuses (Lippincott 2008). Mobile devices offer the opportunity to "dramatically [impact] how libraries deliver services to their users" (Murray 2010, 245); libraries should take advantage of the near-ubiquity of mobile devices among students to better gain their attention (Vassilakaki, Moniarou-Papaconstantinou, and Garoufallou 2016).

\section{Questioning Our Relationship to Mobile Devices}

In short, much of the applied LIS literature over the past ten years has framed the hyperconnectedness and ease of information access facilitated by our mobile devices as a development that libraries should embrace. Implicit in many of these discussions is the assumption that our information consumption via mobile devices, though potentially ubiquitous, is still volitional and under our considered control. We agree that mobile devices have had a substantial impact, much of it positive, on the ways that academic libraries support student learning, and we do not deny that increased ease of information access offers considerable advantages. However, we contend that we need to operate from a fuller understanding of the way in which that information is accessed, as well as the unintended, often unseen, effects of this method of access. This requires an understanding of the role of embodiment in information access.

Research in a number of fields has problematized the idea of an entirely volitional relationship to our mobile devices and the platforms to which they allow access. There is support for this in fields like neuroscience, public health, and psychology, with studies on the positive affective experience of social media use (Mauri et al. 2011), as well as the addictive nature of social media (Kuss and Griffiths 2011) and cell phones (De-Sola Gutiérrez, de Fonseca, and Rubio 2016), and resultant emotional exhaustion (Sriwilai and Charoensukmongkol 2016). We offer a phenomenological analysis because, while we have data on the ubiquity of these devices and the potential that our relationship to them is not entirely volitional (see, for example, Rainie and Zickuhr 2015), phenomenological analysis provides improved understanding of what happens between an individual and her phone. Understanding how her phone is used and how this use remains, for the most part, unthinking will help us find ways to encourage more reflective use of mobile devices. ${ }^{2}$

\section{Merleau-Ponty and the Habits of the Phenomenal Body}

Phenomenology is a philosophical movement and a methodology that aims to describe the structures of human consciousness as experienced by persons (see Heidegger [1927] 1962; Husserl [1913] 1963; Merleau-Ponty [1945] 1962). Phenomenologists explore any number of these structures, including perception, memory, time, sociality, and embodiment (Sokolow- 
ski 2000). What phenomenologists share is the attempt to expose these experiences as they appear before we conceptualize them. Phenomenologists work against "the natural attitude," or our everyday understandings of and beliefs about the world around us. We tend to take for granted the reality of our prereflective grasp on the world, and phenomenologists aim to suspend this natural attitude (Bullington 2013, 19).

In Phenomenology of Perception, Maurice Merleau-Ponty theorizes a key place for human embodiment in phenomenological analysis. ${ }^{3}$ The term used by phenomenologists for the central structure of all human experience and consciousness is intentionality. To say that human consciousness is intentional is to say that consciousness is always consciousness of something and that consciousness "reaches out" toward its object. For his predecessors, embodiment, although considered important to a phenomenological understanding of human nature, was not theorized as central to intentionality in particular. Merleau-Ponty insists, however, that embodiment is crucial to a full understanding of consciousness and intentionality. "Consciousness is being-towards-the-thing through the intermediary of the body" (Merleau-Ponty [1945] 1962, 159-60).

More than this, the body is essential to the development of subjectivity. The body not only offers the medium through which consciousness grasps the world, but determines the bounds of the world and the limits of the subject's ability to make meaning. It is through our bodies that we are "at grips with the world" (Merleau-Ponty [1945] 1962, 353). Bodily comportment is ultimately necessary to and for intelligent comportment; the body is the constituting subject, and the consciousness-world relationship cannot be accounted for without the body and the structures it provides that allow for comprehensible movement and experience. Merleau-Ponty calls this connectedness of embodied consciousness and the world the phenomenal body (121).

Merleau-Ponty ([1945] 1962, xx) references Husserl's notion of operative intentionality in order to further clarify embodied intentionality. For Merleau-Ponty, operative intentionality is fundamentally a bodily intentionality bound up with moving and coping in the world and not bound to consciousness of an object as an intellectual act (Landes 2013, 141). Operative intentionality is conscious embodiments' "I can" (Merleau-Ponty [1945] 1962, 159). It is an intentionality that comes to the fore when the world poses problems for the phenomenal body and the phenomenal body adapts its posture, movement, etc. to address the situation. The phenomenal body exhibits a prereflective knowing that is a bodily knowing.

Merleau-Ponty offers the example of moving around one's flat to illustrate this. "My flat is, for me, not a set of closely associated images. It remains a familiar domain round about me only as long as I still have 'in my hands' or 'in my legs' the main distances and directions involved, and as long as from my body intentional threads run out towards it" (Merleau- 


\section{LIBRARY TRENDS/WINTER 2018}

Ponty [1945] 1962, 150). When a person walks through her home, she need not estimate the distance between her kitchen island and cabinets, nor does she need to turn on the light at night to find the bathroom. There is a knowledge "in her legs" that allows her to avoid the corner of the rug in her bedroom at night and a knowledge "in her hands" that gives her the ability to reach for a pan without thinking while cooking.

The sedimentation of this operative intentionality that would allow one to move around one's home in the way described above is called "habit." Merleau-Ponty writes:

The acquisition of habit is indeed the grasping of a significance, but it is the motor grasping of a motor significance. Now what precisely does this mean? .. . If I am in the habit of driving a car, I enter a narrow opening and see that I can "get through" without comparing the width of the opening with the width of the wings, just as I go through a doorway without checking the width of the doorway against that of my body. ([1945] 1962, 165)

While driving, the bodily actions necessary in order to pilot the car need not be at the forefront of consciousness. Instead, a series of habits allows the driver to drive the car "without thought." The phenomenal body's habits express a harmony between intention and action that is prereflective. More than this, however, the phenomenal body "takes up" the car into the body. To use an object the way one uses the car "is to be transplanted into them, or conversely, to incorporate them into the bulk of our own body" (Merleau-Ponty [1945] 1962, 166). The body not only makes sense of the world and its objects, but offers a unity between the bodysubject and world that involves the taking up of objects to act as extensions of one's phenomenal body.

Habit expresses our power of dilating our being-in-the-world, or changing our existence by appropriating fresh instruments. It is possible to know how to type without being able to say where the letters which make the words are to be found on the banks of keys. To know how to type is not, then, to know the place of each letter among the keys, nor even to have acquired a conditioned reflex for each one, which is set in motion by the letter as it comes before our eye. If habit is neither a form of knowledge nor an involuntary action, what then is it? It is a knowledge in the hands, which is forthcoming only when a bodily effort is made, and cannot be formulated in detachment from that effort. (Merleau-Ponty [1945] 1962, 166)

Our body's ability to form habits and to take up objects in the world as part of those habits offers us a distinct understanding of many objects in the world as manipulable and as objects that extend what we can do. When the phenomenal body encounters an object, unless one adopts an observational attitude toward the object, one uses the object. In the instance of the typewriter above, after one has become familiar with the typewriter, 
once one has used the typewriter for some time, one does not look at the typewriter as a collection of discrete objects (keys, feed roller, paper shelf, etc.), but instead as an object to be used to write. Her bodily habit allows her to use the typewriter "without thought" and, in fact, to incorporate the typewriter into her bodily possibilities through habit. More than this, however, the typewriter might become essential to her for completing her projects. Insofar as she can type, she is a writer.

\section{The Incorporation OF THE SMARTPHONE}

This understanding of habit is important for our understanding of the way in which the smartphone is taken up into bodily habit, "incorporating [it] into the bulk of our own body" (Merleau-Ponty [1945] 1962, 166). In The Absent Body, Drew Leder (1990) expands on Merleau-Ponty's notion of incorporation as the taking up of objects into our bodily habits. Leder explains that "skill acquisition is accomplished via a process I will term incorporation. From the Latin corpus, or 'body,' the etymology of this word literally means to "bring within a body" (30). When we fully incorporate a skill or an object and the skills its use requires, the skill(s) and/or the object become part of our body and its possibilities.

According to Leder, habits initially require "a complex series of thematizations" (Leder 1990, 30). As Leder uses it, thematization refers to the conceptualization of a skill such that it is broken down into specific parts in order to understand and perform said skill. In incorporation, the thematizations are superseded and the acquisition of a new skill comes along with an effacement of these thematizations. Through successful incorporations, skills become prereflective habits. Leder provides the example of a new swimmer to illustrate this. When one first learns how to swim, one must be aware of many different facets of the process of swimming. One must think about how to cup one's hands and kick one's feet, one must concentrate on timing turning one's head and breathing while lifting an arm from the water, etc. With practice, however, this same swimmer will be able to perform these synchronized movements prereflectively.

The original incorporation of the use of a smartphone follows this pattern. ${ }^{4}$ Although I previously owned mobile phones, the adaptation of smartphone technology involved a new and complex set of thematizations. I needed to adjust to the screen serving a dual purpose, both as keyboard and display. I needed to learn to use my thumbs on a digital QWERTY keyboard. I needed to learn how to find and open diverse applications for the various new uses of my phone. This meant "unlocking" my phone with a numerical password, which involved different bodily movements from what I normally associated with phone use, including swiping. Even the weight and size of the phone required adjustment. My hands are small and my first smartphone, the iPhone 4, was heavier and larger than my previous mobiles. I needed to think about the placement of the smartphone in 


\section{LIBRARY TRENDS/WINTER 2018}

my hands in order to avoid dropping it and to be able to reach all of the parts of the screen that my fingers needed to be able to touch. ${ }^{5}$

Eventually these movements became so much a part of my bodily habit that the thematizations were entirely effaced. I no longer need to think about the weight of the phone and its placement in my hand. I do not need to "distance" myself from the phone in order to bring to mind the steps involved in unlocking my phone, locating an application, and opening an application. Like Merleau-Ponty's typewriter, I need not think about the placement of the keyboard keys on my phone as I text. I hardly "think" about my smartphone at all. Leder writes:

As a result of ongoing patterns of action, the body can develop automatic tendencies to repeat. I may fall into unreflective habits concerning waking up and going to sleep, conducting myself on the job, interacting with colleagues, exercising, or relaxing. The vast reach of the "I can" contracts into the "I do," that region of body possibility I actually use. Nor, because of the nature of incorporation, is it easy to excise or even recognize such habits. Over time they simply disappear from view. They are enveloped within the structure of the taken-forgranted body from which I inhabit the world. (1990, 32)

When we incorporate skills or associated objects into our bodily habit, one of the results of that incorporation is the way in which we cease to recognize the extent to which incorporation happens. Skills and objects used consistently become so much a part of what we do that we often forget that performance of the skill was something that required thematization and practice.

What makes the incorporation of the smartphone and associated skills more interesting phenomenologically than the incorporation of other objects is twofold. Although the incorporation of the smartphone follows the same pattern as the incorporation of different objects and skills, the incorporation of the smartphone is distinct because of both the degree to which mobiles are incorporated and the ways in which that incorporation is concealed the longer phones are used. To understand the degree of incorporation and concealment of our smartphones and "to articulate what was previously just lived out" (Taylor 2005, 32), a description of a morning at the author's desk will be considered.

When I arrive at work before I need to teach my first class, I sit at my desk, turn on my computer, and grab my phone from the front pocket of my satchel without thinking about the action, where it always resides when it is not in my hand or on my desk. I start work, but a flash of light alerts me to a new text message. After responding to the text, I realize I forgot to respond to a message I received on Snapchat the night before, so I open the application and respond. A few minutes later, I recognize that I have opened my Facebook application on my phone and am skimming an article about a bill before the House and vaguely remember having 
read something about Sean Spicer tweeting a password. I do not recall what password or the source of this information. Recognizing I must get back to work, I close my phone's open applications, and I realize that I have checked my weather application, my calendar, and my Twitter without having consciously reflected on doing so. Strangely, although I do not remember what I looked at on Twitter or details about the weather forecast for the day, I do note now that I have an appointment with a student I had forgotten.

I return to work, frustrated with myself for being unthinkingly distracted for a few of my precious morning minutes. For the most part, my attention is back on my MacBook, but the time on my computer's clock is not correct, so I find that I am checking my phone's time every 4-5 minutes. One time, without initially recognizing what I am doing, I open the Facebook application, and only realize I have done it several minutes later.

What is striking about this experience is that this is all happening within a half hour's time and I have done these things on my phone and not my computer. Although my computer's screen is larger and I can type faster on my computer than my phone, it is my phone my hand picks up. Moreover, when I begin an activity that requires concentrated attention, I usually "hide" my phone. It is not enough to put it in my satchel-my hand reaches into my bag without my consciously reflecting on the action, often without awareness of the particular reason I reach for the object. It knows where my smartphone is, so I put my phone on a bookshelf out of reach.

This brief account of my morning is in some ways unremarkable, but in others, quite illustrative. When I think about the centrality of my smartphone to my morning's activities, I realize my smartphone is an object unlike others for me-there is no other object which is constantly on my person and to which I turn so frequently. Although we do not make the claim that the use of the smartphone described above describes every person's relationship to their smartphone, the purpose of offering this description is not to offer a universal account of smartphone use, but to open a space of reflection for the reader. Just as Leder's "phenomenological example" of digestion $(1990,38)$, Merleau-Ponty's descriptions of the typewriter and driving, as well as other similar phenomenological descriptions offered by philosophers (for example, Heidegger's hammer ([1927] 1962, 98) or Husserl's inkpot ([1900] 2001, 291), this description is offered in order to render what was familiar and unreflected upon less familiar and open to interpretation. This sort of illustration allows for clearer application of the phenomenological concepts discussed above to persons' embodied relationships to their smartphones, though makes no claim to the universality of the relationship as it is described. The value of this sort of analysis lies not in its claims to universality of description, but in the reflective attitude it inspires in readers and researchers.

Merleau-Ponty's and Leder's explanations of habit and incorporation 
are particularly helpful for articulating the facets of my relationship to my smartphone and for understanding why and how it has obtained this status of object-unlike-any-other. We postulate that there are three features of the relationship between my body and my smartphone that are best understood in light of incorporation and habit. First, there is no other object that has been incorporated into my bodily schema so thoroughly. Second, my smartphone and my use of it is concealed from me in ways that are unparalleled. Finally, when my smartphone "has my attention," whether it is a reflective attention or a prereflective attention, my intentionality fundamentally changes. We will discuss these in turn.

The extreme level of incorporation is the clearest feature of my relationship to my smartphone. Incorporation is both temporal and spatial. It is temporal because the smartphone and its use have become part of my body's temporal history (Leder 1990, 32). Over time my body's repeated, frequent use of this device "trains" my body to become used to having my smartphone ready to hand. This contributes to the spatial incorporation of my phone as an ever-present and literally ready-to-hand tool that my body has taken up as part of its schema. The smartphone requires so little of me, especially since temporally it has been part of my habits for eight years, that I have physically incorporated it like no other tool. It is always "on" me and ready to hand (Lasen 2004). I have my phone out in class because many of my classrooms do not have clocks (or functioning clocks). I have it on me when I am out to dinner, whether in my purse or on the table. I have my phone while I am watching television. Often, only after my phone is in my hand and I have opened an application to check on a tangential thought I have (e.g., I wonder how much this actor is paid) will I realize I have picked it up. My use of my phone in this instance is as prereflective as grabbing the blanket draped over the back of my couch when my feet get cold.

This lack of recognition of the extent to which the smartphone has become incorporated points to the way in which the smartphone and its use are concealed. Concealment refers to the way in which the smartphone and skills I have acquired in order to use it "simply disappear from view. They are enveloped within the structure of the taken-for-granted body from which I inhabit the world" (Leder 1990, 32).

There are three ways in which my smartphone brings with it concealment, whether its own concealment or concealment it produces. First, there is functional concealment. This is the sort of concealment of most sorts of devices (Borgmann 1987). My smartphone is a tool that requires very little of me. As to its upkeep, the operating system and applications update automatically. Until the end of my phone's life, the phone's processing is fast and there is near instantaneous access to any application. Unlocking the phone and opening applications requires little in the way of physicality or conscious thought given the level at which I have incorporated my smartphone. 
Furthermore, given just how little my smartphone requires of me, the way in which it allows me to extend my "I can" with ease is worth remark. If I forget to send a gift to my mom for Mother's Day, I can do it in less than two minutes with the tap of a finger to open my Amazon application, and a few more taps. I can use my Android Pay app when I forget my wallet and want a coffee at the campus Starbucks. I can use my smartphone to call someone at a distance. I can see my niece 1400 miles away in Minnesota instantaneously through Google Hangouts. I can check my email, listen to podcasts, watch Netflix, look at the campus gossip with any number of applications designed for anonymous posting. The incredible range of options available to me through this small and unimposing device can only remain unthought of in our daily lives because of the unparalleled functional concealment this device brings.

The functional concealment of my smartphone is related to its physical concealment. My smartphone is small compared to a computer or a tablet. It is light. It requires almost no energy to pick it up and put it down. I can carry it without fatiguing and easily forget that I am holding it. It fits into my pocket as well as palm. There are any number of products available that make specific room for my smartphone (purses, wallets) as well as allow me to attach it to my body (belt clips, runner's bands). My smartphone's physical concealment, given its size and the ways I have found to attach it to me, is practically a foregone conclusion.

Interestingly, it is not only that I feel comfortable with having my phone "on" me, it has been taken up so thoroughly into my phenomenal body that I feel more comfortable with my phone than I do without it. I feel out of sorts and anxious without my phone. When I realize I have forgotten my phone, something like a sense of "dread" settles in initially. How will I remember what is on my calendar for the day? Will I miss a meeting? Will I remember to print all the documents for the meetings, now that I cannot access them on my smartphone? Even driving to the grocery after work is experienced differently than it was before. I wonder whether that light that has been blinking on my dash is really just a simple wiring issue, and what I will do if my car breaks down. When it is "on" me, my phone might go unnoticed for hours. When I am without it, however, its absence interrupts my regular activities. The absence of my phone is more available to me than its presence. This speaks to exceptional levels of concealment and incorporation.

The third type of concealment is what I will call a "world" concealment. My smartphone distances me from other possibilities and experiences without my explicit recognition that it does this. Things in my world fade from my recognition, and I can experience "a reduction of certain possibilities of encounter" (Leder 1990, 180). When I pick up my smartphone, my intentionality is directed toward a screen that both cuts off my attention to localized presences and pulls my attention to something not-physically-present. While sometimes my attention is directed toward a 
person who is not physically present (e.g., my niece in Minnesota) or to something that allows me to work on a project that is present (e.g., finding a needed article), often my smartphone just distracts me. I mindlessly scroll through Facebook, passively absorbing pictures of cute animals and headlines about potential nuclear disasters in turn. Given social norms, it is often taken for granted by many that smartphones will be out and used during personal and professional gatherings; thus, even being in the presence of actual others does not prevent me from withdrawing from the social world into the worlds given to me by my smartphone's screen. This world concealment is hard to fight against, even when I recognize the ways in which my smartphone is detrimental to my attention and focus. I know my smartphone distances me from what is present even at times I do not want to be distanced from what is present, but my hand also knows where my phone is.

The extreme concealment and incorporation of smartphones is especially interesting for information literacy because of the third feature of my body's relationship to my smartphone. My smartphone offers me constant and unrestricted access to information via mobile applications. In some ways, the access to information granted to me by a smartphone is similar to the access offered by a computer or tablet, but how and how often I access information on my phone is different. When I look something up on my computer or tablet, it requires me to physically locate myself in front of the computer, or in the instance of my tablet, to search for it in blankets on my bed or couch. The same is not usually true of my phone. It is in my purse, to my right on the couch, or already in my hand. The access I have to my phone is unmatched.

Moreover, when I search out my computer or tablet, it is for a purpose. I know that I want to find information or do work, and thus, I find the device that will best allow me to accomplish that work. It is an act of volition when I pick up my computer or tablet. More importantly than this, however, we are often called away from our computers and tablets in regular ways, whether for meetings, or teaching, or to meet bodily needs. For many of us, however, our phones always remain in our pockets, readily accessible and often accessed, even when we are engaged in projects that take us away from our computers or tablets. While I am waiting for coffee to brew, my Facebook application is open on my smartphone before I realize I have picked up my phone, while my computer sits unused on my desk in another room.

How and how often I access information on my smartphone is important insofar as when I access this information on my smartphone, my relationship to the information I am consuming hardly rises to the level of conscious awareness much of the time because of my smartphone's incorporation and concealment. While scrolling through Facebook waiting for a meeting to start, I only partially notice what is written about the United 
States bombing Syria in a friend's post. Part of my attention is taken by my colleague taking the seat next to me and setting up her computer for the meeting. That I am passively absorbing such important and devastating information is cause for pause.

\section{IMPLICATIONS FOR INFORMATION LITERACY}

In the final part of this paper, we return to the applied LIS literature, and consider what this analysis can contribute to how we conceptualize and teach information literacy. We believe there is a place in existing conversations about information literacy to take up the questions of how smartphones function as part of our prereflective bodily habit, what this means for our ability to think critically about the information we access through these devices, and what strategies are possible for disrupting this prereflective relationship. ${ }^{6}$ We will argue that the notion of dispositions, present in the Framework (ACRL 2015) and AASL standards (2007, 2009), among other places, offers a possible lens for understanding how this kind of disrupting could occur.

$$
* * *
$$

As we highlighted at the outset, the library literature has said much about the promise of the mobile technology for ubiquitous information access and communication. While we do not deny that there have been, and continue to be, many positive consequences stemming from increased access and communication, there are challenges, too, as both our analysis and literature from other fields make clear.

What would it look like to incorporate an awareness of the smartphone as a part of our prereflective bodily habit into our information literacy efforts? In addition to exploring its impact on how we consume information, it should include considerations of taking a critical distance to incorporation of the smartphone into our bodily habit, and reflecting on what has heretofore been prereflective. This means recognizing the concealment and incorporation into our bodily habit of what is, for many of us, a primary mechanism for accessing information repeatedly throughout the day, and examining how this incorporation and concealment impact how we consume and reflect on the information accessed.

Disrupting this aspect of our bodily habit will involve becoming conscious of our embodied relationships to our smartphones, and cultivating reflectiveness about what has previously been prereflective. This means drawing back and observing ourselves as we pick up our smartphones throughout the day. Is there a certain emotion or feeling (boredom? anxiety? stress? curiosity?) present when we feel the urge to pick it up? Does picking it up alleviate or exacerbate this feeling? When we notice ourselves scrolling through social media or other information feeds, what informa- 
tion have we consumed? Did we interact with it or think critically about it? Because we are observing not just our thought processes, but our bodily comportment and our emotions, becoming mindful of these aspects of our embodied relationship to our smartphones involves more than metacognition. Indeed, we could think of this disruption of our bodily habit as a way of incorporating new and more intentional habits, with the goal that eventually they become incorporated so fully that they are our default.

\section{Finding a Place for Disrupting in Existing Information Literacy Discussions}

Are the practices described above compatible in any sense with existing notions of information literacy? Running alongside dominant understandings of information literacy as a set of cognitive skills and competencies, exemplified by the Association of College \& Research Libraries' (ACRL) Information Literacy Competency Standards for Higher Education (2000), have been alternative accounts that emphasize the role of the affective domain in the information experience. The affective domain "comprises a person's attitudes, emotions, interests, motivation, self-efficacy, and values" (Schroeder and Cahoy 2010, 130). In the 1980s, scholars Constance Mellon and Carol Kuhlthau developed theories of library anxiety and the Information Search Process (ISP), respectively, both of which operated from an understanding of the research and information-seeking process as involving significant affective components (Schroeder \& Cahoy 2010, 132). Research into the affective dimension of information literacy has continued throughout subsequent decades, contributing to a "new perspective of information literacy research and practice where the information seeker was viewed as a whole person" (Kay and Ahmadpour 2015, 4).

Although educational objectives are often articulated in a way that separates cognitive, affective, and psychomotor dimensions, this separation is not actually possible in "real-life learning situations" (Martin and Briggs 1986, 9). Learning how to disrupt this bodily habit will involve elements that can be recognized as cognitive, affective, and corporeal. In the analysis offered above, for example, in order for the author to have disrupted her prereflective relationship to her phone, she would have needed to have brought to her awareness several things. Knowing, as she does, the prereflective nature of her relationship to her smartphone, she would have needed to assess whether on the given day and at the given time she was alert enough to keep her smartphone next to her. In the morning, this author often feels a little sluggish and anxious while thinking about the day ahead and the classrooms she needs to run. She is often easily distracted in the first hour of her work because of her lack of alertness and energy. Knowing her predilection toward anxiousness, her lessened ability to maintain focus, and her general bodily sluggishness, she recognizes that putting her phone in a desk drawer might help combat the unthinking way in which she reaches for her phone. Without assessing her bodily, cognitive, and affective states like this, however, it is likely she would un- 
thinkingly put her phone to the right of her computer as she always does. Understanding disrupting in this way is in keeping with Merleau-Ponty's notion of embodied consciousness, where the body is essential to the development of subjectivity and our ability to make meaning in the world, and thus an inseparable part of learning any cognitive or affective skill.

Disrupting Bodily Habit as a Disposition. One avenue for thinking about how these practices can be incorporated into existing discussions about information literacy is through the concept of dispositions. This concept, sometimes referred to as "thinking dispositions" (Tishman and Andrade 1996), developed out of the fields of educational psychology and philosophy of education, and occurs in information literacy scholarship and professional association documents, including the American Association of School Librarians' (AASL) Standards for the 21st-Century Learner (2007) and Standards for the 21st-Century Learner in Action (2009) and the Association of College \& Research Libraries' (ACRL) Framework for Information Literacy for Higher Education (2015)

Dispositions have been defined as "tendencies toward particular patterns of intellectual behavior" (Tishman and Andrade 1996, under "How are Thinking Dispositions Defined?" para. 1), such as "mindfulness," "pay[ing] attention to given context," and "[being] open to new information" (under "What Kinds of Thinking Dispositions Are There?" para. 3). The American Association of School Librarians defines dispositions as "the learning behaviors, attitudes, and habits of mind that transform a learner from one who is able to learn to one who actually does learn" (AASL 2009, 14); examples include maintaining a critical stance and asking questions of information sources. In the ACRL Framework, dispositions are the "affective, attitudinal, or valuing dimension of learning" that ought to develop alongside cognitive proficiencies or "knowledge practices" in the process of becoming information literate (2015, under "Introduction," para. 2). Implicit in the notion of a disposition is the insight that thinking well involves more than just cognitive or intellectual ability. It must also include certain "motivations, attitudes, values and habits of mind" (Tishman and Andrade 1996, under "Introduction," para. 1), such as a "critical spirit" and a "probing inquisitiveness" (Kwon, Onwuegbuzie, and Alexander 2007, 270).

The concept of dispositions has been taken up in LIS scholarship as a way to think about addressing hurdles to information literacy that are not purely cognitive. Kwon, Onwuegbuzie, and Alexander (2007) urge librarians to nurture in students positive dispositions toward critical thinking as a way to overcome library anxiety. Schroeder and Cahoy (2010) draw on a Delphi study that found numerous affective dispositions associated with critical thinking (Facione 1990) to offer a model of information literacy that incorporates affective dispositions into student learning outcomes. And Folk $(2016,303)$ argues that librarians should "value" and "promote" 
dispositions toward lifelong learning and higher-order thinking in working with students.

The practice of disrupting described above, with its emphasis on cultivating not just the ability but the habit of being mindful and reflective, can be understood as a type of dispositional tendency, and in this way, can be brought into conversation with existing literature on the role of dispositions in information literacy. We would go farther, however, and suggest that the concept disposition be expanded to include the tendency or motivation to pay attention not only to one's intellectual and affective behavior but also to one's bodily comportment. Just as the description of one of the author's mornings with her smartphone was designed to promote reflection in the reader about her own use of her smartphone, the concept of disposition in LIS and education literature allows for the cultivation of "new information" in students through their own reflections on how their smartphones actually appear in their daily dealings. Moreover, having students reflect on the ways in which our bodies affect the way in which we access and interact with information and devices that deliver information should be acknowledged as an important part of fostering advantageous dispositions in students. In other words, this particular disposition involves cultivating a critical spirit not only toward our thinking and feeling about the information we encounter but also toward our embodied relationship with our smartphones and the ways in which this prereflective relationship mediates our information experiences.

\section{Conclusion}

Merleau-Ponty's description of the role of human embodiment in consciousness, and specifically the habits of the phenomenal body, and Leder's expansion on Merleau-Ponty's research into the phenomenal body, offer a rich foundation for theorizing our embodied relationship to information via our smartphones. Understanding the role of embodiment in information access allows us to operate from a fuller understanding of the way in which information is accessed, as well as the unintended, often unseen, effects of this method of access. This requires an understanding of the role of embodiment in information access. With this paper, we have drawn on Merleau-Ponty and Leder to offer an analysis of the body's relationship to the smartphone using phenomenological concepts, and to think through some of the implications for information literacy. How our smartphones are incorporated into our prereflective bodily habits, and what this means for how we interact with and consume information, are important questions for those who are interested in information literacy to consider.

Can we help cultivate the disposition described above in the information literacy classroom? Some have argued that thinking dispositions are best taught through enculturation - that is, by using "exemplars, interac- 
tion, and instruction" to foster a culture in the classroom that values these dispositions (Tishman and Jay 1993, 150). We admit that it is likely impossible to establish a classroom culture within a single information literacy session. Therefore, opportunities will need to be found to work with students for a sustained period of time, either in cooperation with a course faculty member or through a credit-bearing information literacy course. Developing activities and coursework that help students learn to suspend their everyday attitudes regarding their smartphones and educating them on some of the phenomenological concepts in this paper may very well be an important step to encouraging a curiosity about the ways in which their relationship to their smartphones is more complicated than it might originally seem. Further research into how best to acquaint students with applied phenomenological thinking is a necessary next step for application of our theoretical findings in the classroom. ${ }^{7}$ We hope that our research will lead others to explore how our embodied relationships to mobile devices mediate how we consume and interact with information, and what this means for future information literacy efforts.

\section{Notes}

1. For a clear statement of the intent of applied philosophical phenomenology, see EddlesHirsch's "Phenomenology and Educational Research" (2015, 251). Like Eddles-Hirsch, we maintain the importance of qualitative reflection on the experience of a phenomenon and the meaning that experience creates in the world of the subject and believe this sort of analysis offers important information that might not be discovered in traditional empirical research. Merriam (2009) and Christensen, Johnstone, and Turner (2010) also address the methodological distinctions between empirical research and phenomenological analysis.

2. Here we follow the example of Connell (1996) and Barnacle (2009). Connell explores the implications of Don Ihde's phenomenology of technology in order to explain how best to use and instruct students how to use computers, expressly addressing the importance of critical reflection on the use of technology in our everyday lives. It is a mistake, the author explains, to approach computer use merely as the use of any other tool (6). Instead, the author insists we must see that technologies, like computers, have a sort of intentionality and change humans' relationships to and perception of their environments (12). Barnacle (2009) writes on the advances of understanding of the role of the body in learning, specifically the way in which the phenomenological models of Merleau-Ponty and Dreyfus, among others, posit a central place for the body in understanding and learning. Barnacle argues that the recognition of the centrality of the body means that the old trope of the "life of the mind" is no longer sufficient for understanding learning and that "informal modes of knowing in learning," including embodied knowing, must be explored (32). Our project runs parallel to these projects insofar as we look to explore how phenomenological aspects of embodiment affect the way in which we understand the use of one particular form of technology, the smartphone.

3. Little in LIS has been written on the work of Merleau-Ponty. What has been written about Merleau-Ponty often comes as part of an author offering a general background in phenomenology in order to argue for the potential relevance of phenomenological analysis to information science work (see, for example, Budd 2005; Fenwick 2003; and Wilson 2003), yet few account for Merleau-Ponty's theories pertaining to embodiment. Marjorie O'Loughlin (1998) discusses the importance of Merleau-Ponty's work for a proper understanding of the body in education. She critiques postmodern accounts of the body and uses Dewey, Nietzsche, and Merleau-Ponty as "resources for rehabilitating a notion of human embodiment that is at once material, individual and social" (275). O'Loughlin does not 


\section{LIBRARY TRENDS/WINTER 2018}

restrict her treatment to Merleau-Ponty and only suggests how Merleau-Ponty's work might shape more specific future discussions. Annemaree Lloyd (2014) argues for the centrality of bodies in information experience by examining the experience of emergency service personnel and exploration of the "role of body as a locus for understanding and meaning making" (85). Her philosophical focus in analysis, however, is not strictly Merleau-Pontian. She offers a philosophical account of the body in Foucault and Dewey, as well (89).

4. The shift from the first-person plural to the first-person singular here is intentional. The author writing this section is offering an individual phenomenological analysis of her own experience. She is detailing her own experience with her smartphone in order to describe her phone as it actually appears in everyday experience. This requires bringing to the fore of contemplation that which normally remains unthought. This form of observation requires inner observation and an attempt to suspend the natural attitude spoken of above to get at the phenomenon as it is encountered in immediate, prereflective experience. The use of the first-person singular here is methodologically more appropriate than the use of the first-person plural.

5. There is a diverse and fairly substantial phenomenology of telephony literature, but what we seek to accomplish here is different from what has been previously written. The literature in phenomenology of telephony can roughly be broken down into three "types" of literature. One part of the literature offers a phenomenology of the mobile phone qua mobile phone. For instance, Michael Arnold (2003) exposes the mobile's Janus-faced nature and explains that the mobile is "not reducible to a direction or valence tipped with a single arrowhead, but better understood as a conflation of tangential implications" (234). He does not rely on an explicitly phenomenological methodology, however. Ingrid Richardson's work (2005 and 2007) comes closer to offering "phenomenologies" of the mobile phone, but her use of phenomenology more closely aligns with "empirical phenomenology" as defined by social scientists (see, for instance, Groenewald 2004; Hein and Austin 2001; and Kafle 2013).

Another segment of the literature is concerned with the way in which mobile devices have shifted our experience of space and time. Anthony Townsend (2002) coins the term "phonespace" to indicate the way in which mobile devices have made the possibility of interruption ubiquitous (70). He argues that given this possibility of a person to interrupt us at any time in any place, mobile phones have redefined temporal and spatial patterns of sociality. Related analysis on the effect of mobile media on spatiality, especially locative media, are also found in the literature (see Farman 2012 and Lasen 2004).

We discovered one philosophical, phenomenologically grounded analysis of the mobile phone offered in the phenomenology of telephony literature. In "Where are You? A Heideggerian Analysis of the Mobile Phone," Fernando Ilharco (2007) offers a phenomenological analysis of the mobile phone rooted in the work of Heidegger, but does not offer an extended account of embodied intentionality or reference the work of Merleau-Ponty.

6. Barnacle (2009) is instructive here. Barnacle writes on the advances of understanding of the role of the body in learning, specifically the way in which the phenomenological models Merleau-Ponty and Dreyfus, among others, posit a central place for the body in understanding and learning. Barnacle argues that the recognition of the centrality of the body means that the old trope of the "life of the mind" is no longer sufficient for understanding learning and that "informal modes of knowing in learning," including embodied knowing, must be explored (32). The concept of dispositions also challenges the idea that the "life of the mind" and learning are strictly cognitive, that is, removed from affect, embodiment, etc.

7. We have some helpful examples of the integration of phenomenological reflection into the classroom to follow. Helberg, Heyes, and Rohel (2009) detailed the importance of educating students in both somatic theory and somatic practice in a course dedicated to yoga and philosophy. In the course, students applied theory, including concepts from Drew Leder's work, in order to better understand their embodied practices (276). Standal and Engelsrud (2011) look at the potential place of phenomenology in physical education contexts, specifically rehabilitation centers and dance students, asking students to reflect on their embodied experiences using phenomenologically inspired questions and lines of inquiry. Østergaard, Dahlin, and Hugo (2008) offer helpful examples of the integration of phenomenological methods and concepts into the classroom in "Doing Phenomenology 
in Science Education: A Research Review." They explain that incorporating education in phenomenology into science education curriculum is a way to "ground' scientific concepts in concrete lifeworld experience" (106). They detail the work of two scientists, Michael Faraday, who took an experimental approach to scientific study and " [let] nature speak for herself" (108), and Martin Wagenschein, who argued against "the division of the world into a part that can be sensed and experienced and a theoretical part" (110).

\section{REFERENCES}

AASL (American Association of School Librarians). 2007. "Standards for the 21st-Century Learner." http://www.ala.org/aasl/sites/ala.org.aasl/files/content/guidelinesandstandards/learningstandards/AASL_LearningStandards.pdf.

- 2009. Standards for the 21st-Century Learner in Action. Chicago: American Library Association.

ACRL (Association of College \& Research Libraries). 2015. Framework for Information Literacy for Higher Education. http://www.ala.org/acrl/standards/ilframework.

2000. Information Literacy Competency Standards for Higher Education. http://www.ala. $\mathrm{org} / \mathrm{acrl} / \mathrm{standards} /$ informationliteracycompetency.

Anderson, Monica. 2015. "Technology Device Ownership: 2015." Pew Research Center: Internet, Science $\mathcal{E}$ Tech. http://www.pewinternet.org/2015/10/29/technology-device-ownership-2015.

Arnold, Michael. 2003. "On the Phenomenology of Technology: The 'Janus-Faces' of Mobile Phones." Information and Organization 13 (4): 231-56. https://doi.org/10.1016/S14717727(03)00013-7.

Barnacle, Robyn. 2009. "Gut Instinct: The Body and Learning." Educational Philosophy and Theory 41 (1): 22-33. https://doi.org/10.1111/j.1469-5812.2008.00473.x.

Barnhart, Fred D., and Jeannette E. Pierce. 2011. "Becoming Mobile: Reference in the Ubiquitous Library." Journal of Library Administration 51 (3): 279-90. https://doi.org/10.1080 /01930826.2011.556942.

Borgmann, Albert. 1987. Technology and the Character of Contemporary Life: A Philosophical Inquiry. Chicago: University of Chicago Press.

Breeding, Marshall. 2006. "The Systems Librarian: Technology for the Next Generation." Computers in Libraries 26 (10): 28-30. http://proxy.lib.ohio-state.edu/login?url=http:// search.ebscohost.com/login.aspx?direct=true \&db=rzh\&AN=106292145\&site=ehost-live.

Bridges, Laurie, Hannah Gascho Rempel, and Kimberly Griggs. 2010. "Making the Case for a Fully Mobile Library Web Site: From Floor Maps to the Catalog." Reference Services Review 38 (2): 309-20. https://doi.org/10.1108/00907321011045061.

Budd, John M. 2005. "Phenomenology and Information Studies." Journal of Documentation 61 (1): 44-59. https://doi.org/10.1108/00220410510578005.

Bullington, Jennifer. 2013. The Expression of the Psychosomatic Body from a Phenomenological Perspective. New York: Springer.

Christensen, Larry B., R. Burke Johnson, and Lisa A. Turner. 2010. Research Methods, Design, and Analysis. 11th ed. Boston: Allyn \& Bacon.

Connell, Jeanne M. 1996. "Exploring Some of the Educational Implications of Ihde's Philosophy of Technology." Educational Foundations 10 (4): 5-12. http://proxy.lib.ohio-state .edu/login?url=https://search-proquest-com.proxy.lib.ohio-state.edu/docview/1468389 576 ?accountid $=9783$.

Cowell, Amanda E., and Jia Mi. 2016. "Doing Research on Mobile Devices: An Undergraduate Case Study." College E Undergraduate Libraries 23 (4): 414-26. https://doi.org/10.108 $0 / 10691316.2015 .1025938$.

Dahlstrom, Eden, J. D. Walker, and Charles Dziuban. 2014. "ECAR Study of Undergraduate Students and Information Technology." EDUCAUSE. https://library.educause.edu/ /media/files/library/2014/10/ers1406.pdf.

De-Sola Gutiérrez, José, Fernando Rodríguez de Fonseca, and Gabriel Rubio. 2016. "Cell-Phone Addiction: A Review." Frontiers in Psychiatry 7. https://doi.org/10.3389/fpsyt.2016.00175.

Dold, Claudia Jennifer. 2016. "Rethinking Mobile Learning in Light of Current Theories and Studies." Journal of Academic Librarianship 42 (6): 679-86. https://doi.org/10.1016/j .acalib.2016.08.004. 


\section{LIBRARY TRENDS/WINTER 2018}

Dukic, Zvjezdana, Dickson K. W. Chiu, and Patrick Lo. 2015. "How Useful Are Smartphones for Learning? Perceptions and Practices of Library and Information Science Students from Hong Kong and Japan.” Library Hi Tech 33 (4): 545-61. https://doi.org/10.1108 /LHT-02-2015-0015.

Eddles-Hirsch, K. 2015. "Phenomenology and Educational Research." International Journal of Advanced Research 3 (8): 251-60. http://www.journalijar.com/article/5631/phenome nology-and-educational-research.

Facione, Peter A. 1990. "Critical Thinking: A Statement of Expert Consensus for Purposes of Educational Assessment and Instruction. Research Findings and Recommendations." https://eric.ed.gov/?id=ED315423.

Farman, Jason. 2012. Mobile Interface Theory: Embodied Space and Locative Media. New York: Routledge.

Fenwick, Tara. 2003. "Reclaiming and Re-Embodying Experiential Learning through Complexity Science." Studies in the Education of Adults 35 (2): 123-41. https://doi.org/10.108 0/02660830.2003.11661478.

Fling, Brian. 2009. Mobile Design and Development: Practical Concepts and Techniques for Creating Mobile Sites and Web Apps. Sebastopol, CA: O'Reilly Media.

Foley, Marianne, and Katherine Bertel. 2015. "Hands-on Instruction: The iPad Self-Guided Library Tour." Reference Services Review 43 (2): 309-18. https://doi.org/10.1108/RSR-07 -2014-0021.

Folk, Amanda L. 2016. "Academic Reference and Instruction Librarians and Dweck's Theories of Intelligence.” College Eं Research Libraries 77 (3): 302-13. https://doi.org/10.5860 /crl.77.3.302.

Groenewald, Thomas. 2004. “A Phenomenological Research Design Illustrated.” International Journal of Qualitative Methods 3 (1): 42-55. https://doi.org/10.1177/160940690400300104.

Heidegger, Martin. (1927) 1962. Being and Time. Translated by John Macquarrie and Edward Robinson. New York: Harper \& Row.

Hein, Serge F., and Wendy J. Austin. 2001. "Empirical and Hermeneutic Approaches to Phenomenological Research in Psychology: A Comparison.” Psychological Methods 6 (1): 3-17. https://doi.org/10.1037/1082-989X.6.1.3.

Helberg, Natalie, Cressida J. Heyes, and Jaclyn Rohel. 2009. "Thinking through the Body: Yoga, Philosophy, and Physical Education.” Teaching Philosophy 32 (3): 263-84. https://doi .org/10.5840/teachphil200932328.

Hennig, Nicole. 2016. "Mobile Learning Trends: Accessibility, Ecosystems, Content Creation." Library Technology Reports 52 (3): 1-38. http://proxy.lib.ohio-state.edu/login?url=http:// search.ebscohost.com/login.aspx?direct=true\&db=lih\&AN=115233967\&site=ehost-live.

Hopkins, Peta, Jo Hare, Jessie Donaghey, and Wendy Abbott. 2015. "Geo, Audio, Video, Photo: How Digital Convergence in Mobile Devices Facilitates Participatory Culture in Libraries.” Australian Library Journal 64 (1): 11-22. https://doi.org/10.1080/00049670.2014.984379.

Hudson, Alexia. 2010. "Measuring the Impact of Cultural Diversity on Desired Mobile Reference Services.” Reference Services Review 38 (2): 299-308. https://doi.org/doi:10 $.1108 / 00907321011045052$.

Husserl, Edmund. (1900) 2001. The Shorter Logical Investigations. Translated by J. N. Findlay. New York: Routledge.

—. (1913) 1963. Ideas: A General Introduction to Pure Phenomenology. Translated by W. R. Boyce Gibson. New York: Collier Books.

Ilharco, Fernando. 2007. "Where Are You? A Heideggerian Analysis of the Mobile Phone." Comunicação Ẽ Cultura 3: 59-76. http://repositorio.ucp.pt/handle/10400.14/10380.

Jacobs, Michelle Leigh. 2009. "Libraries and the Mobile Revolution: Remediation=Relevance." Reference Services Review 37 (3): 286-90. https://doi.org/10.1108/00907320910982776.

Kafle, Narayan Prasad. 2013. "Hermeneutic Phenomenological Research Method Simplified." Bodhi: An Interdisciplinary Journal 5 (1): 181-200. https://doi.org/10.3126/bodhi.v5i1.8053.

Kay, Robin H., and Kamran Ahmadpour. 2015. "Negotiating the Digital Maze of Information Literacy: A Review of Literature.” Journal of Educational Informatics 1: 1-25. http://www .journalofeducationalinformatics.ca/wp-content/uploads/2016/04/JEI-2015-01_Kay_Ah madpour_FINAL.pdf.

Kuss, Daria J., and Mark D. Griffiths. 2011. "Online Social Networking and Addiction-A Review of the Psychological Literature." International Journal of Environmental Research and Public Health 8 (9): 3528-52. https://doi.org/10.3390/ijerph8093528. 
Kwon, Nahyun, Anthony J. Onwuegbuzie, and Linda Alexander. 2007. "Critical Thinking Disposition and Library Anxiety: Affective Domains on the Space of Information Seeking and Use in Academic Libraries." College $\mathcal{E}$ Research Libraries 68 (3): 268-278. https://doi .org/10.5860/crl.68.3.268.

Landes, Donald A. 2013. The Merleau-Ponty Dictionary. New York: Bloomsbury.

Lasen, Amparo. 2004. "Affective Technologies: Emotions and Mobile Phones." Receiver 11 (3): $1-8$.

Leder, Drew. 1990. The Absent Body. Chicago: University of Chicago Press.

Lippincott, Joan K. 2008. "Mobile Technologies, Mobile Users: Implications for Academic Libraries.” ARL 261. http://files.eric.ed.gov/fulltext/ED503858.pdf.

— 2010. "A Mobile Future for Academic Libraries." Reference Services Review 38 (2): 205-13. http://doi.org/10.1108/00907321011044981.

Lloyd, Annemaree. 2014. "Informed Bodies: Does the Corporeal Experience Matter to Information Literacy." In Information Experience: Approaches to Theory and Practice, edited by Christine Bruce, Helen Partridge, Kate Davis, and Hilary Hughes, 85-99. Library and Information Science Series 9. Bingley, UK: Emerald Group.

Martin, Barbara L., and Leslie J. Briggs. 1986. The Affective and Cognitive Domains: Integration for Instruction and Research. Englewood Cliffs, NJ: Educational Technology.

Mauri, Maurizio, Pietro Cipresso, Anna Balgera, Marco Villamira, and Giuseppe Riva. 2011. "Why Is Facebook so Successful? Psychophysiological Measures Describe a Core Flow State while Using Facebook." Cyberpsychology, Behavior and Social Networking 14 (12): 723-31. https://doi.org/10.1089/cyber.2010.0377.

Merleau-Ponty, Maurice. (1945) 1962. Phenomenology of Perception. Translated by Colin Smith. New York: Routledge Classics.

Merriam, Sharan B. 2009. Qualitative Research: A Guide to Design and Implementation. Jossey-Bass Higher and Adult Education Series. San Francisco: Jossey-Bass.

Moores, Shaun. 2009. "That Familiarity with the World Born of Habit: A Phenomenological Approach to the Study of Media Uses in Daily Living." Interactions: Studies in Communication E Culture 1 (3): 301-12. https://doi.org/10.1386/iscc.1.3.301_1.

Murray, Lilia. 2010. "Libraries 'Like to Move It, Move It.” Reference Services Review 38 (2): 233-49. https://doi.org/10.1108/00907321011045007.

O'Loughlin, Marjorie. 1998. "Paying Attention to Bodies in Education: Theoretical Resources and Practical Suggestions." Educational Philosophy $\mathcal{E}$ Theory 30 (3): 275. https://doi .org/10.1111/j.1469-5812.1998.tb00328.x.

Østergaard, Edvin, Bo Dahlin, and Aksel Hugo. 2008. "Doing Phenomenology in Science Education: A Research Review." Studies in Science Education 44 (2): 93-121. https://doi .org/10.1080/03057260802264081.

Rainie, Lee, and Kathryn Zickuhr. 2015. “Americans' Views on Mobile Etiquette." Pew Research Center: Internet, Science $\mathcal{E}$ Tech. http://www.pewinternet.org/2015/08/26/americans-views -on-mobile-etiquette.

Richardson, Ingrid. 2005. "Fcj-032 Mobile Technosoma: Some Phenomenological Reflections on Itinerant Media Devices." Fibreculture Journal, no. 6. http://six.fibreculturejournal .org/fcj-032-mobile-technosoma-some-phenomenological-reflections-on-itinerant-media -devices.

- 2007. "Pocket Technospaces: The Bodily Incorporation of Mobile Media." Continuum 21 (2): 205-15. https://doi.org/10.1080/10304310701269057.

Schroeder, Robert, and Ellysa Stern Cahoy. 2010. "Valuing Information Literacy: Affective Learning and the ACRL Standards." Portal: Libraries and the Academy 10 (2): 127-46. https:// doi.org/10.1353/pla.0.0096.

Sokolowski, Robert. 2000. Introduction to Phenomenology. New York: Cambridge University Press.

Sriwilai, Kanokporn, and Peerayuth Charoensukmongkol. 2016. "Face It, Don’t Facebook It: Impacts of Social Media Addiction on Mindfulness, Coping Strategies and the Consequence on Emotional Exhaustion." Stress and Health 32 (4): 427-34. https://doi.org/10.1002 /smi.2637.

Standal, Øyvind F., and Gunn Engelsrud. 2011. "Researching Embodiment in Movement Contexts: A Phenomenological Approach." Sport, Education and Society 18 (2): 154-66. https://doi.org/10.1080/13573322.2011.608944.

Taylor, Charles. 2005. "Merleau-Ponty and the Epistemological Picture." In The Cambridge 


\section{LIBRARY TRENDS/WINTER 2018}

Companion to Merleau-Ponty, edited by Taylor Carman and Mark B. N. Hansen, 26-49. Cambridge: Cambridge University Press.

Tishman, Shari, and Albert Andrade. 1996. "Thinking Dispositions: A Review of Current Theories, Practices, and Issues." Cambridge, MA. Project Zero, Harvard University. http:// www.lsalearning.com/wp-content/uploads/2012/09/Dispositions.pdf.

Tishman, Shari, and Eileen Jay. 1993. "Teaching Thinking Dispositions: From Transmission to Enculturation." Theory into Practice 32 (3): 147. http://proxy.lib.ohio-state.edu /login?url=http://search.ebscohost.com/login.aspx?direct=true\&db=aph\&AN=931122 $0793 \&$ site $=$ ehost-live.

Townsend, Anthony M. 2002. "Mobile Communications in the Twenty-First Century City." In Wireless World: Social and Interactional Aspects of the Mobile Age, edited by Barry Brown and Nicola Green, 62-77. New York: Springer.

Turner, Phil. 2008. "Towards an Account of Intuitiveness." Behaviour E Information Technology 27 (6): 475-82. https://doi.org/10.1080/01449290701292330.

Vassilakaki, Evgenia, Valentini Moniarou-Papaconstantinou, and Emmanouel Garoufallou. 2016. "Identifying the Uses of Mobile Technology among Library and Information Science Undergraduate Students.” Program 50 (4): 417-30. https://doi.org/10.1108/PROG-10 -2015-0069.

Wilson, Sally, and Graham McCarthy. 2010. "The Mobile University: From the Library to the Campus.” Reference Services Review 38 (2): 214-32. https://doi.org/10.1108/00907321011044990.

Wilson, T. D. 2003. "Philosophical Foundations and Research Relevance: Issues for Information Research.” Journal of Information Science 29 (6): 445-52. https://doi .org/10.1177/0165551503296002.

Maria Howard, Ph.D., is an assistant professor of philosophy at Gonzaga University. She earned her doctorate from Loyola University Chicago in 2014. Her primary areas of research are in the ethics of assisted suicide, the connections between continental philosophy and bioethics, and foundational philosophical pedagogy.

Hilary Bussell is an assistant professor and social sciences librarian at The Ohio State University. She earned her Master of Science in Library and Information Science from the University of Illinois at Urbana-Champaign in 2012. Prior to this, she earned her Master of Arts in philosophy from Loyola University Chicago, focusing on continental philosophy. Her current research interests are in the areas of interdisciplinary research practices, information literacy, and gender in librarianship. 